\begin{abstract}
MRS ZAHRA CHEGINI (Orcid ID : 0000-0001-9125-9453)
DR SHEIKH MOHAMMED SHARIFUL ISLAM (Orcid ID : 0000-0001-7926-9368)

Article type : Special Issue Paper

\section{Missed Nursing Care and Related Factors in Iranian Hospitals: A Cross Sectional Survey}

\footnotetext{
Running Head: Missed Nursing Care in Iranian Hospitals

Zahra Chegini $\mathrm{PhD}^{1,2}$, Tohid Jafari-Koshki $\mathrm{PhD}^{3}$, Marzieh Kheiri PhD Candidate ${ }^{4}$, Ali Behforoz BSc ${ }^{1}$, Saeedeh Aliari Msc ${ }^{1}$, Udita Mitra Msc ${ }^{5}$, Sheikh Mohammed Shariful Islam PhD ${ }^{6}$

${ }^{1}$ Social Determinants of Health Research Center, Qazvin University of Medical Sciences, Qazvin, Iran

${ }^{2}$ Iranian Center of Excellence in Health Management, School of Management and Medical Informatics, Tabriz University of Medical Sciences, Tabriz, Iran

${ }^{3}$ Molecular Medicine Research Center, Department of Statistics and Epidemiology, Faculty of Health, Tabriz University of Medical Science, Tabriz, Iran

${ }^{4}$ Department of Health Education and Promotion, Faculty of Health, Iran University of Medical Science, Tehran, Iran

${ }^{5}$ School of Health in Social Science, University of Edinburgh, Edinburgh, United Kingdom

${ }^{6}$ Institute for Physical Activity and Nutrition, Deakin University, Geelong, Australia
}

Correspondence address: Zahra Chegini, Social Determinants of Health Research Center, Qazvin University of Medical Sciences, Qazvin, Iran. Shahid Bahonar Blvd, Qazvin, Iran. Tel: +98 2833239259

Email: z.cheginy@gmail.com

This article has been accepted for publication and undergone full peer review but has not been through the copyediting, typesetting, pagination and proofreading process, which may lead to differences between this version and the Version of Record. Please cite this article as doi: $\underline{10.1111 / J O N M .13055}$

This article is protected by copyright. All rights reserved 


\section{Abstract}

Background: Despite providing high-quality patient care in hospitals, nurses often fail to deliver optimum care which jeopardizes the safety of patients and increases health care costs. Identifying missed nursing care is essential therefore if the quality of health services is to be improved. This study, focused on Iranian hospitals, aimed to determine the prevalence of, and reasons for, missed care by nurses and the factors associated with it.

Methods: A cross-sectional study was conducted among 215 nurses working in the medical-surgical wards of eight public and private hospitals in Tabriz, Iran. The 'MISSCARE' survey tool was used to collect data in relation to the extent of missed care and the related reasons. Logistic regression models were used to assess the association between factors and missed nursing care.

Results: Results showed that the mean score of overall missed nursing care was 2.57 and $72.1 \%$ of nurses reported that they commonly missed at least one nursing care on their last shift. "Patient discharge planning and teaching", "emotional support to patient and/or family" and "attend interdisciplinary care conferences whenever held" were the most common missed items by nurses in Iran. In a 5-point Likert scale, the most important reasons identified by nurses for missed care were "human resources" 3.11 (95 \% CI: 3.03-3.19), "material resources" 2.7 (95 \% CI: 2.6-2.8), and “communication" 2.4 (95\% CI: 2.3-2.5) respectively. Missed nursing care was associated with sex (OR for males $=2.83,95 \%$ CI: $1.01-7.89)$, age $(\mathrm{OR}=1.16,95 \% \mathrm{CI}: 1.01-1.33)$ and the number of patients under care $(\mathrm{OR}=1.11,95 \% \mathrm{CI} 1.01-1.22)$. Reverse association was found with the number of patients discharged (OR $=0.89,95 \%$ CI: $0.82-0.96)$ and satisfaction with teamwork (OR $=0.60$, 95\% CI: 0.41-0.89).

Conclusions: There is a need to identify the factors contributing to the incidence of missed nursing care in hospitals and to develop strategies to address these.

Implications for Nursing Management: The results of this study highlighted the importance of addressing missed nursing care in Iranian public and private hospitals. Nursing management should 